\title{
Comparing the Effect of Coconut Oil Pulling Practice with Chlorhexidine Mouth Wash in Plaque Induced Gingivitis by Evaluation of Salivary Biochemical Marker - A Comparative Interventional Study
}

\author{
Sriram Kaliamoorthy ${ }^{1 *}$, Jayasuriya Vijayakumar ${ }^{2}$, Santhosh Kumar Caliaperoumal ${ }^{3}$, Ambiga \\ Pazhani ${ }^{4}$, Kanmani Raju ${ }^{5}$, Padmavathi Venkatesan ${ }^{6}$, Vikneshan Murugaboopathy ${ }^{7}$ \\ 1,2,3\&6Department of Dentistry, Vinayaka Missions Medical College, Vinayaka Mission's Research Foundation \\ (Deemed to be University) ,Karaikal - 609 609, Puducherry, India; ksrirammds@gmail.com \\ 4 Department of Oral Medicine \& Radiology, Vivekananda Dental College \& Hospital, \\ Thiruchencode - 637 205, Tamilnadu India \\ ${ }^{5}$ Department of Oral Medicine \& Radiology, Chettinad Dental College \\ and Research Institute, Kelambakkam - 603 103, Tamilnadu India \\ 7 Department of Public Health Dentistry, Indira Gandhi Institute of \\ Dental Sciences, Sree Balaji Vidhyapeeth (Deemed to be \\ University), Puducherry - 607 403, India
}

\section{Abstract}

Background: Oil pulling is an oral hygiene practice and is described in the ancient Ayurvedic literature. Materials and Methods: A total of 30 subjects with plaque related mild - moderate gingivitis in the age Group of 18-25 was recruited and they were divided into two Groups as Group A and B, each with 15 subjects. Group A subjects were advised to practice coconut oil pulling therapy and Group B subjects were advised to use Chlorhexidine Gluconate $0.12 \%$ solution for 4 weeks as an adjuvant practice along with routine tooth brushing. Estimation of salivary Aspartate Aminotransferase was done at pre and post intervention stage for both the study Groups by using semi auto analyser. Results: Statistically significant reduction in the reduction in the salivary Aspartate Aminotransferase level was seen at post intervention stage in Group A and Group B compared to preintervention stage. Comparison of salivary Aspartate Aminotransferase level between Group A subjects and Group B subjects at pre and post intervention stage revealed no significant difference. Our study results show that oil pulling utilizing coconut oil is effective in reducing the severity of plaque induced mild-moderate gingivitis and the effect is comparable to $0.12 \%$ chlorhexidine mouthwash in reducing plaque formation and gingivitis. Conclusion: Oil pulling utilizing coconut oil is an effective adjuvant oral hygiene practice in reducing the severity of plaque induced mild - moderate gingivitis along with the routine oral hygiene measure. Coconut oil pulling practice could be a potential alternative to chlorhexidine mouth wash for long term use.

Keywords: Ayurveda, Aspartate Aminotransferase, Kavala Gandoosha, Kavala Graham, Oil Swishing

\section{Introduction}

Oral cavity is habitat for variety of microorganisms which includes both commensals and pathogenic organisms.
Daily practice of oral hygiene measures is essential to maintain good oral health. Mechanical cleansing of teeth by tooth brushing and mouth rinsing using mouth wash are the common method practiced to maintain the good 
oral health. Long term use of mouth wash found to be associated with adverse effects like altered sensation and staining of teeth ${ }^{1}$.

Oil pulling or oil swishing is an ancient oral hygiene practice. Ayurvedic texts such as Charaka Samhita and Sushruta Samhita describe it as 'Kavala Graha' or 'Kavala Gandoosha'. In oil pulling, a tablespoon of oil is swished around the mouth for about 20 minutes and after the oil turns milky and thinner, it should be spit out followed by thorough washing of mouth by clean water ${ }^{3,4}$.

Oils such as sunflower oil, sesame oil and coconut oil are commonly used edible oil for cooking. Coconut oil contains high concentration of lauric acid which is a medium chain fatty acid. High saponification index of coconut oil facilitates effective cleansing action and reduces plaque and debris formation. Also, lauric acid has effective anti-inflammatory and anti-microbial properties ${ }^{5}$.

Studies on oil pulling using coconut oil are limited. ${ }^{6}$ In the available studies on oil pulling using edible oils, gingival and plaque index was used to assess the effectiveness of oil pulling in reducing the severity of gingivitis ${ }^{6,7}$. Aspartate Aminotransferase (AST) in the recent years is considered as a most promising biochemical marker of tissue destruction. Salivary AST level is correlated with disease severity in chronic gingivitis ${ }^{8-11}$.

With this background the current study was undertaken to compare the effect of coconut oil pulling with standard and most commonly used chlorhexidine mouth wash in plaque induced gingivitis patients by estimation of salivary AST at pre and post intervention stage.

\section{Materials and Methods}

A prospective interventional study was done to compare the effectiveness of oil pulling therapy using coconut oil in plaque related gingivitis. Institutional ethical committee approval was obtained.

A total of 30 subjects formed the study population for this study. The inclusion criteria are subject with plaque related mild - moderate gingivitis in the age Group of 18-25 years.

The exclusion criteria were 1 . History of dental treatment in the past 6 months, 2. Antibiotic, steroid and hormonal therapy in the past 6 months, 3. Tobacco smoking and chewing, 4. Pregnancy and lactating mother, 5. Systemic diseases and 6. Unwillingness to participate in the study.

Informed written consent was obtained from the selected study subjects and they were divided into two Groups i.e. Group A and B, each with 15 participants and were age and sex matched. Evaluation of salivary Aspartate Aminotransferase was done at the start of the study and kept as baseline value for all the study subjects in Group A and B.

Group A subjects were advised to perform coconut oil pulling i.e. to take tablespoon of edible coconut oil and swish it around the mouth and spit it into the trash once it turns viscous before brushing and consuming fluids. They were advised to continue the procedure everyday in the morning for 4 weeks.

Subjects in the Group B were advised to rinse the mouth with $15 \mathrm{ml}$ of undiluted Chlorhexidine Gluconate $0.12 \%$ solution for 30 seconds twice daily for 4 weeks. They were advised strictly to avoid drinking water or consume any food immediately after mouthwash rinse.

Frequent oral examination was done for all the study subjects during the study period. None of the study subjects reported with any adverse effects associated with the practice.

After 4 weeks, post intervention salivary Aspartate Aminotransferase was assessed for all the study subjects in Group A and Group B.

\subsection{Collection of Saliva Sample}

Study subjects were advised to avoid eating or drink for 30 minutes before sample collection. They were instructed to rinse the mouth with distilled water and sit with head slightly tilting forward without oral movements for few minutes. This was followed by collection of pooled saliva in the floor of the mouth, in the sterile plastic container. The container was sealed immediately and sent for processing.

\subsection{Processing Saliva Sample and Estimation of Salivary Aspartate Aminotransferase Levels}

The collected saliva samples were centrifuged at 3000 RPM for 10 minutes. The centrifuged samples 
Table 1. Comparison between pre intervention and post intervention mean salivary Aspartate Aminotransferase (AST) level in Group A (coconut oil pulling Group)

\begin{tabular}{|c|c|c|c|c|c|c|}
\hline Group & & Mean & $\mathbf{N}$ & $\begin{array}{l}\text { Standard } \\
\text { Deviation }\end{array}$ & Mean difference & P-value \\
\hline \multirow{2}{*}{$\begin{array}{l}\text { Group A } \\
\text {-Coconut oil } \\
\text { pulling Group }\end{array}$} & $\begin{array}{l}\text { Pre intervention stage salivary } \\
\text { AST level U/L }\end{array}$ & 32.193 & 15 & 13.9388 & \multirow[b]{2}{*}{5.433} & \multirow[b]{2}{*}{$<0.001^{*}$} \\
\hline & $\begin{array}{l}\text { Post intervention stage (After } 4 \\
\text { weeks) salivary AST level U/L }\end{array}$ & 26.760 & 15 & 12.1634 & & \\
\hline
\end{tabular}

*denotes statistically significant Wilcoxon signed rank test as $\mathrm{p}<0.05$

Table 2. Comparison between pre intervention and post intervention mean salivary AST level in Group B (Chlorhexidine Gluconate mouthwash Group)

\begin{tabular}{|c|c|c|c|c|c|c|}
\hline Group & & Mean & $N$ & $\begin{array}{l}\text { Standard } \\
\text { Deviation }\end{array}$ & Mean difference & P-value \\
\hline \multirow{2}{*}{$\begin{array}{l}\text { Group B - } \\
\text { Chlorhexidine } \\
\text { Gluconate } \\
\text { Mouthwash } \\
\text { Group }\end{array}$} & $\begin{array}{l}\text { Pre Intervention stage AST level } \\
\mathrm{U} / \mathrm{L}\end{array}$ & 26.580 & 15 & 11.8840 & \multirow{2}{*}{6.567} & \multirow{2}{*}{$<0.001^{*}$} \\
\hline & $\begin{array}{l}\text { Post Intervention stage (After } 4 \\
\text { weeks) AST level U/L }\end{array}$ & 20.013 & 15 & 9.8761 & & \\
\hline
\end{tabular}

*denotes statistically significant Wilcoxon signed rank test as $\mathrm{p}<0.05$

Table 3. Comparison of pre-intervention salivary AST level between Group A and Group B

\begin{tabular}{lllllll}
\hline Group & N & Mean & Std. Deviation & $\begin{array}{l}\text { Mean } \\
\text { difference }\end{array}$ & P-value \\
\hline \multirow{2}{*}{$\begin{array}{l}\text { Pre Intervention } \\
\text { stage AST level U/L }\end{array}$} & $\begin{array}{l}\text { Group - A (Coconut oil } \\
\text { pulling Group) }\end{array}$ & 15 & 32.193 & 13.939 & & \\
\cline { 2 - 5 } $\begin{array}{l}\text { Group B (Chlorhexidine } \\
\text { Gluconate mouthwash }\end{array}$ & 15 & 26.580 & 11.884 & $0.245^{\mathrm{NS}}$ \\
\hline \begin{tabular}{l} 
Group) \\
\hline
\end{tabular}
\end{tabular}

NS- denotes not statistically significant using Mann Whitney U test $\mathrm{p}>0.05$

Table 4. Comparison of post-intervention salivary AST level between the two Group A and Group B

\begin{tabular}{lllllll}
\hline Group & & N & Mean & Std. Deviation & Mean difference & P-value \\
\hline & $\begin{array}{l}\text { Group A (Coconut oil } \\
\text { Proup ) }\end{array}$ & 15 & 26.760 & 12.163 & 6.747 & $0.107^{\mathrm{NS}}$ \\
\cline { 2 - 5 } $\begin{array}{l}\text { stage (After 4 weeks) } \\
\text { AST level U/L }\end{array}$ & $\begin{array}{l}\text { Group B (Chlorhexidine } \\
\text { Gluconate mouthwash } \\
\text { Group) }\end{array}$ & 15 & 20.013 & 9.876 & \\
\hline
\end{tabular}

NS- denotes not statistically significant using Mann Whitney U test $\mathrm{p}>0.05$

were assayed using semiautomatic analyser by IFCC (International Federation of Clinical Chemistry and Laboratory Medicine) method without pyridoxal phosphate.

\section{Results}

Total number of subjects participated in this study was 30. Group A and Group B, each constituted 15 study 
subjects of which 10 were male and 5 were female.

For Group A subject's mean salivary AST level at pre-intervention stage was $32.193 \pm 13.938$ and at post-intervention stage was $26.760 \pm 12.163$. The mean difference was 5.433 and this difference was statistically significant using Wilcoxon signed rank test as $\mathrm{p}<0.05$.

For Group B subject's mean salivary AST level at pre-intervention stage was $26.580 \pm 11.884$ and at post=intervention stage was $20.013 \pm 9.876$. The mean difference was 6.567 and this difference was statistically significant using Wilcoxon signed rank test as $\mathrm{p}<0.05$.

Mean salivary AST level at pre-intervention stage for Group A subject was $32.193 \pm 13.938$ and for Group $\mathrm{B}$ was $26.580 \pm 11.884$. The mean difference was 5.613. This difference was not statistically significant using Mann-Whitney U test as $\mathrm{p}<0.05$.

Mean salivary AST level at post-intervention stage for Group A was $26.760 \pm 12.163$ and for Group B was $26.580 \pm 11.884$. The mean difference was 6.747 . This difference was not statistically significant using Mann-Whitney $\mathrm{U}$ test as $\mathrm{p}<0.05$.

\section{Discussion}

Tooth brushing using tooth paste is the most accepted practice for the maintenance of routine oral hygiene. Synthetic mouthwashes are prescribed for individuals with active gingival and periodontal disease as an adjuvant oral health care measure. Alteration of taste sensation and staining of teeth are some of the common side effects associated with chronic mouthwash use.

Oil pulling or swishing is a traditional healing practice described in the Ayurvedic literature.

Sesame oil, sunflower oil and coconut oil are commonly used in the Indian cooking and studies on oil pulling using these oils are available in the literature $e^{6,12,13}$.

Coconut oil is unique for its abundant lauric acid contents which is a medium chain fatty acid. Lauric acid possesses effective cleaning action and prevents the plaque formation and accumulation. Also lauric acid has anti-inflammatory and antimicrobial properties ${ }^{5}$.
In the present study, effectiveness of oil pulling using coconut oil was compared with $0.12 \%$ Chlorhexidine Gluconate mouthwash. Salivary Aspartate Aminotransferase was used as a biomarker to assess the severity of gingivitis.

In this study, at post intervention stage, statistically significant reduction of salivary Aspartate Aminotransferase level was seen with both the Group i.e. Group A subjects who practiced oil pulling therapy and Group B subjects who used $0.12 \%$ Chlorhexidine Gluconate mouthwash, compared to the pre intervention stage.

Peedikayil et al. ${ }^{6}$ studied the effect of coconut oil pulling practice on plaque related gingivitis. They found significant decrease in the plaque and gingival indices score after coconut oil pulling therapy compared to the pre intervention stage. Similar findings were seen in Group A subjects in our study i.e. significant reduction in the severity of gingivitis at post intervention stage after coconut oil pulling therapy, revealed by the reduction in the salivary Aspartate Aminotransferase level.

Also comparison of salivary Aspartate Aminotransferase level between Group A subjects and Group B subjects at pre and post intervention stage revealed no significant difference.

The above findings indicate that coconut oil pulling therapy is as effective as $0.12 \%$ Chlorhexidine Gluconate mouthwash use in reducing plaque formation and gingivitis.

\section{Conclusion}

Based on the findings, we conclude that oil pulling utilizing coconut oil is an effective adjuvant oral hygiene practice in reducing the severity of plaque induced mild - moderate gingivitis along with the routine oral hygiene measure. Coconut oil pulling practice could be a potential alternative to Chlorhexidine mouth wash for long term use.

\section{Acknowledgement}

The completed research was approved and certified by ICMR. 


\section{Conflicts of Interest}

Nil

\section{References}

1. Van Strydonck DA, Demoor P, Timmerman MF, Van derVelden U, Van der Weijden GA. The anti-plaque efficacy of a chlorhexidine mouthrinse used in combination with tooth brushing with dentrifice. J Clin Periodontal. 2004; 31:691-5. PMid: 15257749. https://doi.org/10.1111/j.1600051X.2004.00546.x

2. Sooryavanshi S, Mardikar BR. Prevention and treatment of diseases of mouth by Gandoosha and Kavala. Anc Sci Life. 1994; 13:266-70. PMid: 22556659 PMCid: PMC3336527.

3. Hebber A, Keluskar V, Shetti A. Oil pulling - Unraveling the path to mystic cure. J Int Oral Health. 2010; 2:11-4.

4. T Singh A, Purohit B. Tooth brushing, oil pulling and tissue regeneration: A review of holistic approaches to oral health. J Ayurveda Integr Med. 2011; 2:64-8. PMid: 21760690 PMCid: PMC3131773. https://doi.org/10.4103/09759476.82525

5. Deb Mandal M, Mandal S. Coconut (Cocos nucifera L.: Arecaceae): In health promotion and disease prevention. Asian Pac J Trop Med. 2011; 4:241-7. https://doi.org/10.1016/ S1995-7645(11)60078-3

6. Peedikayil FC, Sreenivasan P, Narayanan A. Effect of coconut oil in plaque related gingivitis - A preliminary report. Niger Med J. 2015; 5:143-7. PMid: 25838632 PMCid: PMC4382606. https://doi.org/10.4103/0300-1652.153406
7. Asokan S, Emmadi P, Chamundeswari R. Effect of oil pulling on plaque induced gingivitis: A randomized, controlled, triple - blind study. Indian J Dent Res. 2009; 20:47-51. PMid: 19336860. https://doi.org/10.4103/09709290.49067

8. Kudva P, Saini N, Kudya H, Saini V. To estimate salivary Aspartate Aminotransferase levels in chronic gingivitis and chronic periodontitis prior and following non-surgical periodontal therapy: A clinic-biochemical study. J Indian Soc Periodontol. 2014; 18:53-8. PMid: 24744545 PMCid: PMC3988645. https://doi.org/10.4103/0972124X.128209

9. Shanbhag VKL. Oil pulling for maintaining oral hygiene - A review. Journal of Traditional and Complementary Medicine. 2017; 7:106-9. PMid: 28053895 PMCid: PMC5198813. https://doi.org/10.1016/j.jtcme.2016.05.004

10. Siddique S, Panchmal GS, Pullishery F. Aspartate Aminotransferase as a biomarker in periodontal disease: A comparative in vitro study. Saudi Journal of Oral Sciences. 2016; 321-24.

11. Podzimek S, Vondrackova L, Duskova, Janatova T, Broukal Z. Salivary markers for periodontal and general disease. Dis Markers. 2016; 2016:9179632. PMid: 27143814 PMCid: PMC4837271. https://doi.org/10.1155/2016/9179632

12. Amith HV, Ankola AV, Nagesh L. Effect of oil pulling on plaque and gingivitis. J Oral Health Community Dent. 2007; $1: 12-8$.

13. Saravanan D, Ramkumar S, Vineetha K. Effect of oil pulling with sesame oil on plaque-induced gingivitis: A microbiological study. J Orofac Res. 2013; 3:175-80. 